\title{
Detection of silent subsidence over extensive area by SBAS DInSAR: a case study of Southern Bali, Indonesia
}

\author{
Putu Edi Yastika $^{1 *}$, Norikazu Shimizu ${ }^{1}$, Ni Nyoman Pujianiki ${ }^{2}$, I Gede Rai Maya Temaja ${ }^{2}$, I \\ Nyoman Gede Antara ${ }^{2}$, and Takahiro Osawa ${ }^{3,4,5}$ \\ ${ }^{1}$ Yamaguchi University, Tokiwadai, 755-8611, Ube, Japan \\ ${ }^{2}$ Udayana University, Jl. P.B. Sudirman, 80234, Denpasar, Indonesia \\ ${ }^{3}$ Centre for Remote Sensing and Ocean Sciences (CReSOS), Udayana University, Jl. P.B. Sudirman, \\ 80234, Denpasar, Indonesia \\ ${ }^{4}$ Centre for Research and Application of Satellite Remote Sensing, Yamaguchi University, \\ Tokiwadai, 755-8611, Ube, Japan \\ ${ }^{5}$ Regional Satellite Applications Center for Disaster Management (RSCD), Satellite Applications and \\ Operations Center (SAOC), Space Technology Directorate, Japan Aerospace Exploration Agency \\ (JAXA), 4-1-1 Industrial Technology Institute Asutopia, Ube, Japan
}

\begin{abstract}
Numerous cities around the world are facing the problem of land subsidence. In many cases, it is the excessive groundwater extraction to meet human needs that leads to this subsidence. Since land subsidence rates are very slow (a few centimeters per year), the subsidence usually remains unnoticed until it has progressed to the point of causing severe damage to buildings, houses, and/or other infrastructures. Therefore, it is very important to detect the presence of subsidence in advance. In this study, screening for the presence of land subsidence in the city of Denpasar, Bali, Indonesia is conducted. The Sentinel-1A/B SAR dataset, taken from October 2014 to June 2019, is processed using the SBAS DInSAR method. Subsidence is found in the districts of Denpasar Selatan, Denpasar Barat, and Kuta, which falls in the range of $-100 \mathrm{~mm}$ to $-200 \mathrm{~mm}$ in an area of about 93.03 ha. All the extracted points of interest show the subsidence having linear behavior. The spatio-temporal behavior of the subsidence in Denpasar is presented clearly. However, the mechanism and the deriving factors of the subsidence remain unclear. Therefore, further studies are needed.
\end{abstract}

\section{Introduction}

Monitoring ground displacement is very important and beneficial for many purposes. Ground displacement measurements can be conducted by geotechnical instruments (e.g., extensometers, inclinometers, etc.), surveying methods (e.g., total stations, levels, etc.), and modern satellite technology (GPS and SAR). GPS is now widely used in the field of geotechnical engineering because it can provide 3-dimensional measurements with high

\footnotetext{
* Corresponding author: eyastika@yamaguchi-u.ac.jp
} 
accuracy [1]. A combination of conventional geotechnical instruments and GPS can be very effective and efficient for application to small to large areas within a few square kilometers.

Land subsidence in an urban area usually occurs on a large scale (tens to hundreds of square kilometers) and with small displacement rates (a few centimeters per year). Since the subsidence rates are small, they often go unnoticed until severe damage has occurred to the ground, e.g., damage to the infrastructure, buildings, or houses. Knowledge of the subsidence in an area is very important for choosing countermeasures to prevent damage. Severe subsidence in urban areas will bring a tremendous socio-economic loss to the local community. Discovering the presence of subsidence before it leads to severe damage is preferable. Therefore, subsidence monitoring is an important task for realizing a sustainable society.

Installing and maintaining geotechnical and GPS instruments over an extensive area is costly and labor expensive. Therefore, an economical and efficient method for monitoring the subsidence over an extensive area is highly required. A time-series analysis of Synthetic Aperture Radar (SAR) data, i.e., Small Baseline Subset Differential SAR (SBAS DInSAR proposed in [2]), is one of the useful tools for monitoring the subsidence over large areas. Through a comparison with the results of a GPS campaign, Yastika et al. (2019) [3] have shown that SBAS DInSAR can yield measurement results with centimeter-order accuracy.

The aim of this study is to detect the unnoticeable subsidence in the southern part of Bali Island, Indonesia. The purpose is to screen a large area of the city of Denpasar and part of Badung Regency to find the presence of "silent subsidence" that might have occurred. A total of 118 Sentinel-1A/B images will be processed using the SBAS DInSAR method. Finally, the spatio-temporal subsidence behavior of the study area will be presented.

\section{Study area and geological setting}

Bali is an island and a province in Indonesia; it is famous around the world for its beauty and many tourist attractions. It has been the main tourist destination in Indonesia for many years. These tourist activities benefit the Balinese economy. However, the development of these activities has been mostly concentrated in South Bali, including the city of Denpasar. The population is also concentrated in that area. In 2016, it was inhabited by 1 million people [4]. Although there have been no reports of subsidence or land surface movements in the area, it is important to conduct an SBAS DInSAR analysis to know the actual land behavior there.

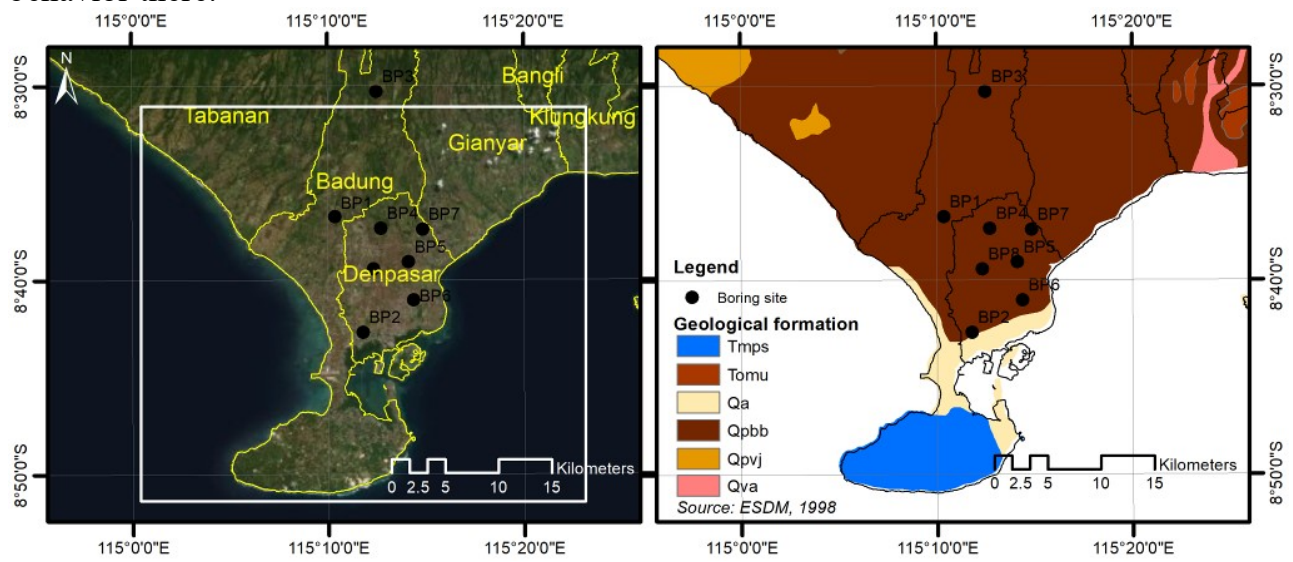

Fig. 1. Location and geological map of study area [5]. 
Geologically, Denpasar lies on the Buyan-Bratan volcanic complex and the Batur Volcanics (Qpbb) formation, mainly consisting of tuff and lahar. The southernmost part of Bali lies on the Selatan formation (Tmps), mainly consisting of reef limestone and marl in places: partly bedded, recrystallized, and fossiliferous. An alluvium formation is found in between the Qpbb and Tmps formations [5]. Figure 1 shows the location and a geological map of the study area. The solid black circles on the map are the locations of the boring holes drilled by the local drinking water company (PDAM). Based on the boring information at eight locations in the figure (BP1-BP8), it was found that mainly sand exists at a depth of $25 \mathrm{~m}$ below the ground surface.

\section{Methods, data collection, and data processing}

\subsection{Outline of SAR and SBAS DInSAR}

"SAR" is the acronym for Synthetic Aperture Radar. Spaceborne SAR is an active sensor mounted on an artificial satellite; it operates all day and all night. Spaceborne SAR is able to generate radar imageries regardless of the weather conditions. This is because it uses electromagnetic radiation with an L, C or X-band that can penetrate clouds. Interferometric SAR (InSAR) is a method for taking the signal phase changes (interference) from two SAR images, which are observed in the same area, but on different dates.

Differential Interferometry SAR (DInSAR) is the common term for the production of interferograms from which the topographic contribution has been removed [6]. The advantage of DInSAR is that it can provide a map of centimeter-scale deformations of the Earth's surface over vast areas of hundreds of square kilometers with a spatial resolution of 3-30 $\mathrm{m}$. The displacement observed by DInSAR is one-dimensional along the satellite line of sight (LOS). Therefore, it needs to be converted to the subsidence or vertical displacement denoted by ' $Z$ '. The horizontal displacement can be ignored by assuming that the subsidence dominates the ground behavior. Under such an assumption, the relationship between the LOS displacement and the subsidence can be expressed by equation (1), where " $\theta$ " is the satellite off-nadir angle.

$$
Z=L O S \text { Displacement } / \cos \theta
$$

To grasp the temporal behavior of the ground deformation, it is necessary to employ multiple SAR data acquired from the same geometries during a certain period. It is referred to as multi-temporal DInSAR (MT-DInSAR). There are two popular MT-DInSAR methods, namely, Permanent Scatters InSAR (PSI) [7] and the Small Baseline Subset DInSAR [2]. These two methods not only provide the temporal behavior of the subsidence, but also improve the measurement accuracy. This study uses the SBAS method which is implemented in the ENVI SARscape 5.5 software

\subsection{Data collection and processing}

To conduct the SBAS DInSAR analysis, this study uses 118 images $(\mathrm{N})$ of Sentinel-1A and Sentinel-1B SAR data. The data acquisition dates span from 16 October 2014 to 16 June 2019 for which the orbit path number is 156 in the descending right-looking observation. All the SAR data were provided by the European Space Agency (ESA) and can be downloaded for free from https://vertex.daac.asf.alaska.edu/\#. To remove the phase component of the topography from the interferograms, a Digital Elevation Model (DEM) with the spatial resolution of $30 \mathrm{~m}$ was used. The DEM data were provided by the Japan 
Aerospace Exploration Agency (JAXA) and can be downloaded for free from https://www.eorc.jaxa.jp/ALOS/en/aw3d30/index.htm.

A time-series DInSAR analysis was then conducted by employing the SBAS DInSAR method. The perpendicular and temporal baseline thresholds were set at $5 \%$ of the critical baseline (Bc) and 96 days, respectively. Accordingly, 981 interferograms were generated and used in the SBAS processing. The Goldstein filter was used to improve the quality of all the interferograms [8], and the Minimum Cost Flow (MCF) method [9] was employed for the interferogram unwrapping. The temporal coherence threshold for unwrapping was set at 0.2. In the final process, the time-series subsidence maps were generated with the spatial resolution of $20 \mathrm{~m}$. At this final step, the coherence threshold was set at 0.4 . Figure 2 shows the baseline table of all the interferograms used in the SBAS processing.

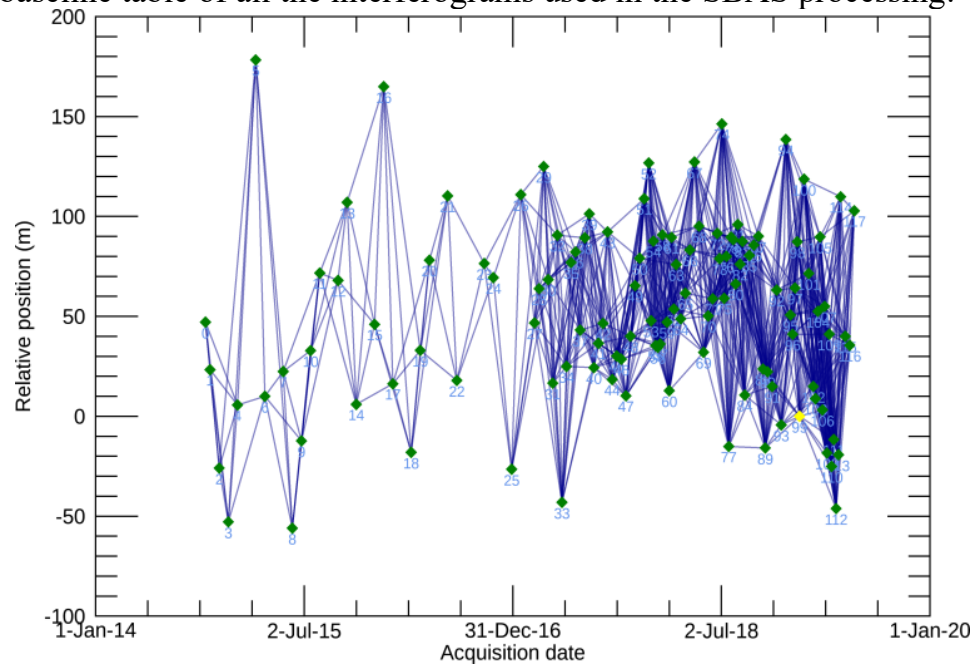

Fig. 2. Time-position plot of all data and interferograms used in SBAS DInSAR processing.

\section{Results and discussions}

\subsection{Spatio-temporal transition of subsidence}

As the SBAS results, $170(\mathrm{~N}-1)$ time-series subsidence maps were generated. Figure 3 shows the cumulative subsidence every October of each year with the last observation date of 16 June 2019, which is given in respect to the first observation date of 16 October 2014. The subsidence maps are given in colors ranging from blue to red which represent subsidence ranging from $+20 \mathrm{~mm}$ to $-200 \mathrm{~mm}$. The area with white means that no results were obtained due to loss of the SAR data coherence which mainly occurred in area with bodies of water or vegetation. Subsidence was found in the southwest part of Denpasar where the color is seen to have turned from blue to red during the observation periods.

To know the transition of subsidence, some points of interest (POI) were arbitrarily selected from the map. The locations of the POI are shown as black circles in Figure 3, and the detailed locations of these points can be found in Figure 5. The transition of subsidence at the POI is shown in Figure 4. No subsidence is found at points B1-B5, B7, or B12-B14. The subsidence up to $100 \mathrm{~mm}$ (the annual average rate: $21 \mathrm{~mm} /$ year) is found at points $\mathrm{B} 6$, B8, B11, B15, and B19. Subsidence of more than $100 \mathrm{~mm}$ and up to $210 \mathrm{~mm}$ (the annual average rate: $21-44 \mathrm{~mm} /$ year) is found at points B9, B10, B16-B18, and B20. All subsiding points show linear behavior. These are the first results of the monitoring in Denpasar by SBAS DInSAR; they show the clear results of the subsidence transition in space and time. 


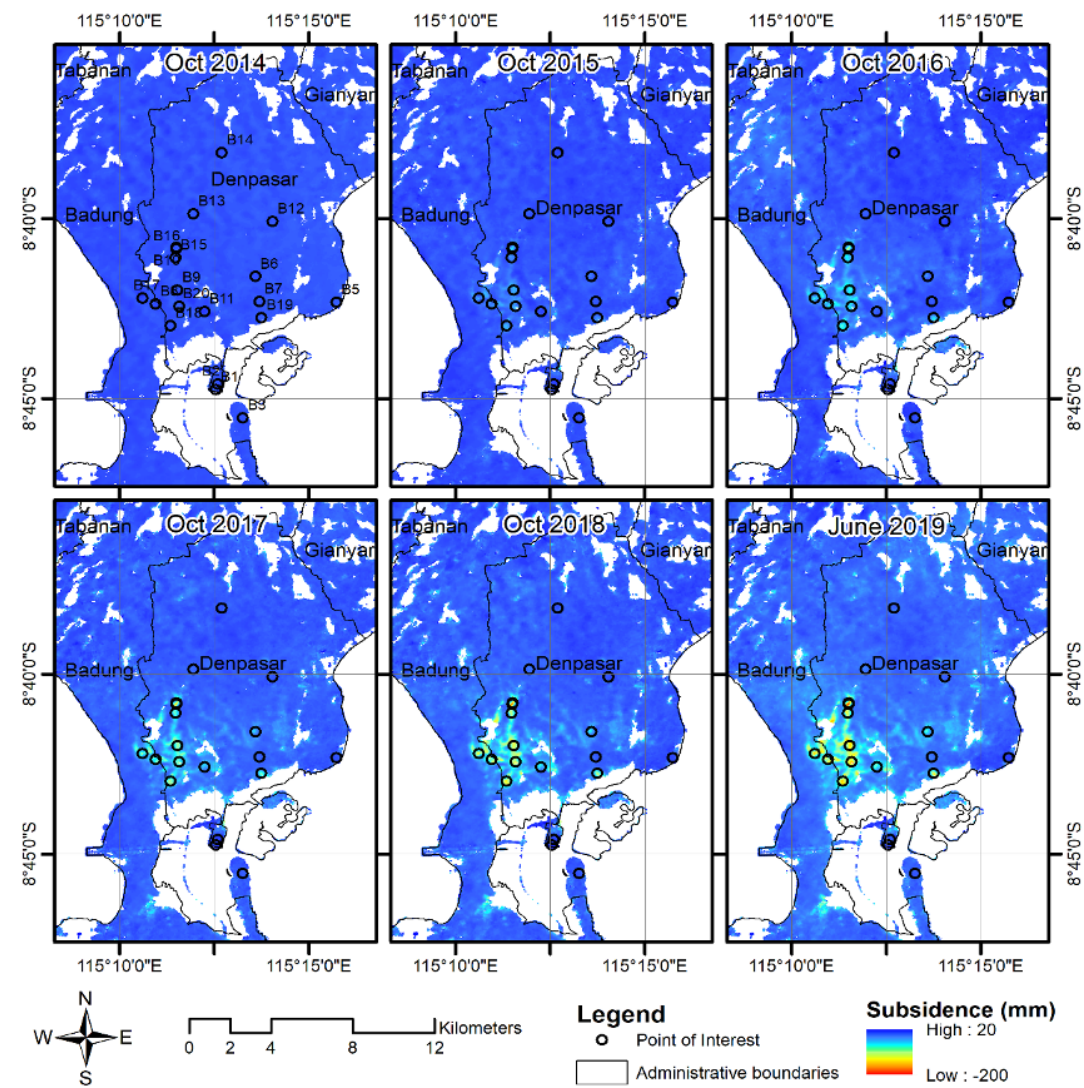

Fig. 3. Time-series subsidence distribution map of Denpasar and its surrounding area.
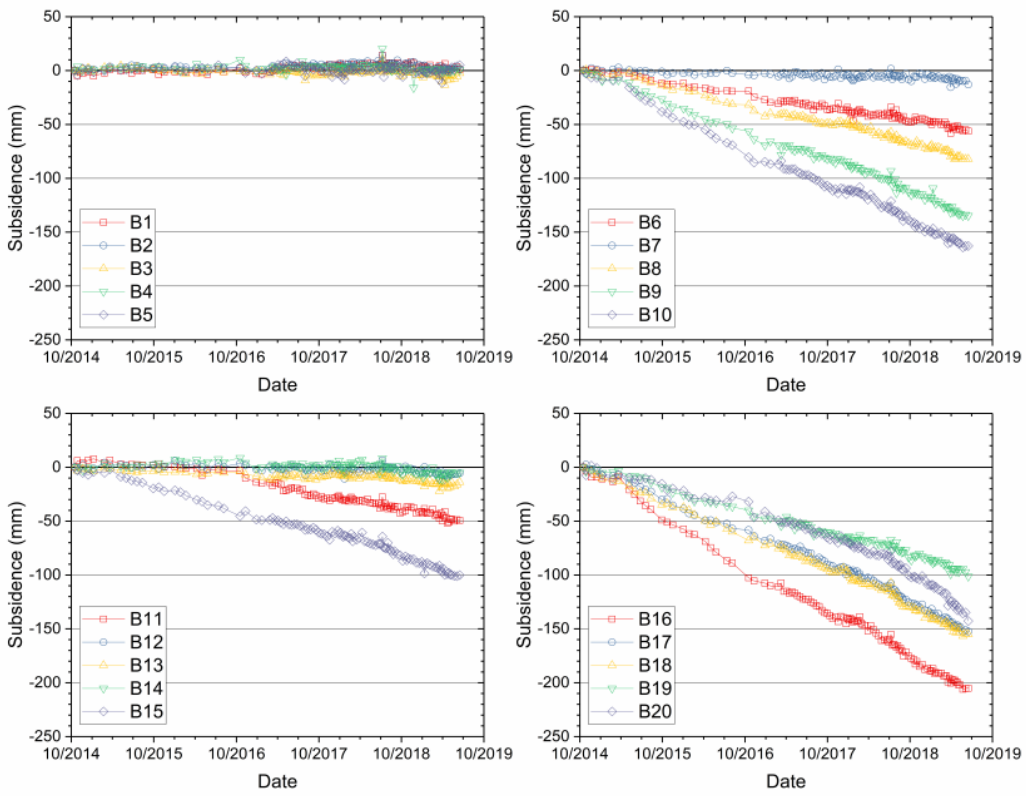

Fig. 4. Subsidence transition during monitoring period at selected points of interest (Oct 2014 - June 2019. 


\subsection{Discussion}

Large subsidence is detected mainly in the districts of Denpasar Selatan, Denpasar Barat, and Kuta. Figure 5 shows the total subsidence occurring from 16 October 2014 to 16 June 2019. Based on their magnitudes, the subsidence is classified into five categories, namely, Category I (+20 - -20 mm: +4 - -4 mm/year), Category II $(-20--50 \mathrm{~mm}:-4--11$ $\mathrm{mm} /$ year), Category III (-50 - -100 mm: $-11--21 \mathrm{~mm} /$ year), Category IV (-100 - -150 mm: $-21--32 \mathrm{~mm} /$ year), and Category V (-150 - -200 mm: -32- $-43 \mathrm{~mm} /$ year). All categorized subsidence is shown on the map in Figure 5. The magnitude of the subsidence was calculated using a spatial analysis tool in a geographical information system (GIS) environment. Table 1 shows the subsidence magnitude for each category for the whole study area. The largest subsidence (Category V) occurred in an area of about 3.21 hectares and more moderate subsidence (Category IV) was found in an area of 89.82 hectares; they are presented in red and orange, respectively, in Figure 5.

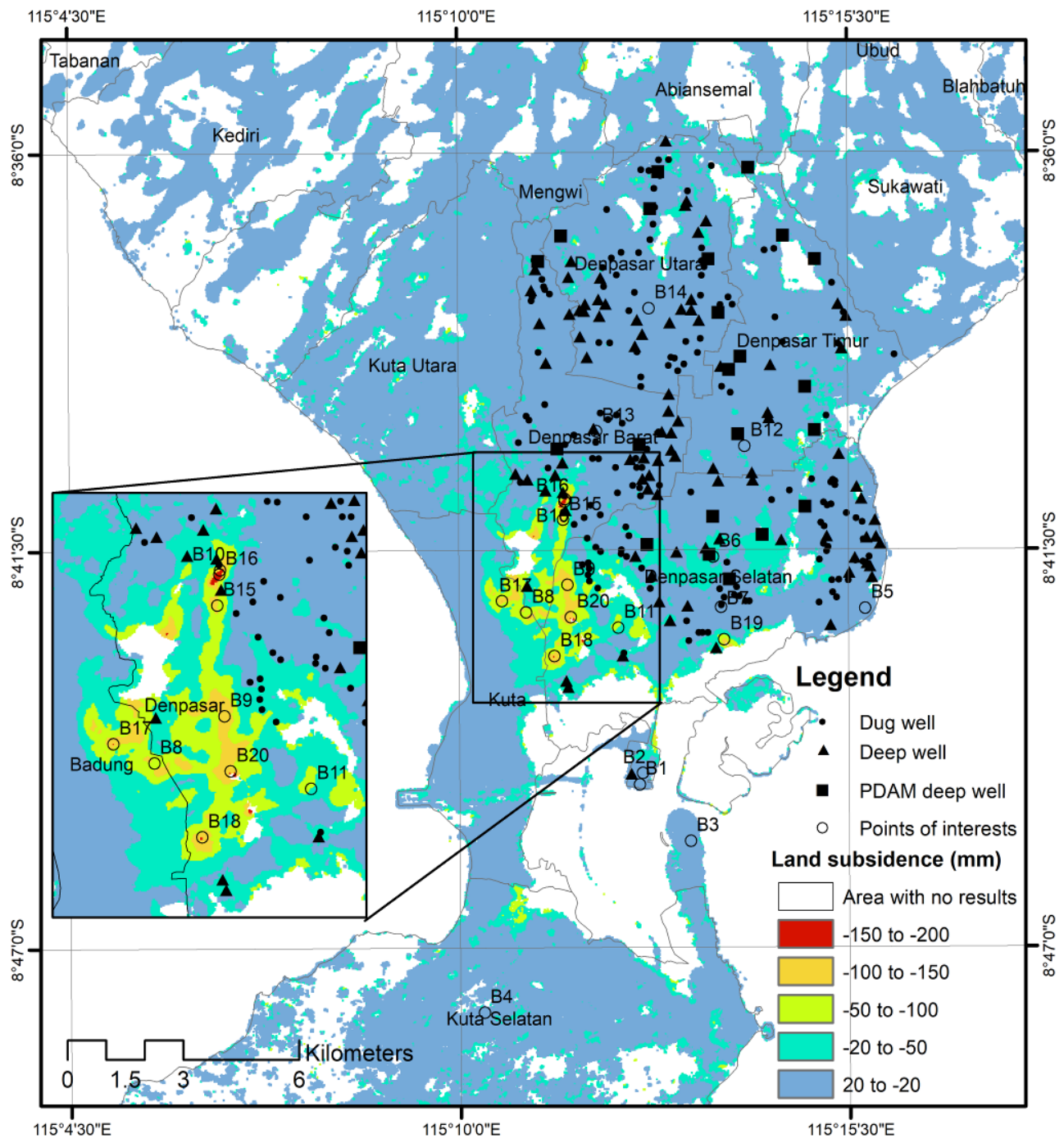

Fig. 5. Map of total subsidence from 16 October 2014 to 16 June 2019 in study area and locations of wells in Denpasar. 
Table 1. Category of subsidence in Denpasar.

\begin{tabular}{|c|c|c|c|}
\hline Category & $\begin{array}{c}\text { Range in subsidence } \\
\text { magnitude (mm) }\end{array}$ & $\begin{array}{c}\text { Range in } \\
\text { subsidence velocity } \\
(\mathbf{m m} / \mathbf{y e a r})\end{array}$ & $\begin{array}{c}\text { Area } \mathbf{( x 1 0 0 0 0} \\
\left.\mathbf{m}^{\mathbf{2}}\right)\end{array}$ \\
\hline I & $+20--20$ & $+4-4$ & 35944.82 \\
\hline II & $-20--50$ & $-4-11$ & 4197.26 \\
\hline III & $-50--100$ & $-11--21$ & 512.48 \\
\hline IV & $-100--150$ & $-21--32$ & 89.82 \\
\hline V & $-150--200$ & $-32--43$ & 3.21 \\
\hline
\end{tabular}

The causes of the subsidence in this area remain unclear. Based on subsidence research in other places, however, it can be said that the subsidence was mainly caused by several factors such as the geological/geomechanical conditions, the load on the ground, groundwater extraction, underground excavations, earthquakes, etc. $[2,10,11]$ demonstrated the applicability of satellite technology, GPS and SAR, for observing land subsidence. Having groundwater extraction data is very important for grasping the factors that lead to subsidence. Unfortunately, this information has not been well documented for this area. The locations of shallow wells (traditional dig wells) and deep wells in Denpasar, namely, those built from 2011-2014, are shown by solid black circles and triangles, respectively, in Figure 5. The locations of the deep wells belonging to the local drinking water company (PDAM) are shown by solid black squares. The locations of the wells are distributed evenly in the non-subsidence and subsidence areas. Therefore, it is difficult to find the reason for the subsidence by only looking at the locations of the wells. Details on the geological/geomechanical conditions of the ground and the groundwater extraction data for each well are necessary.

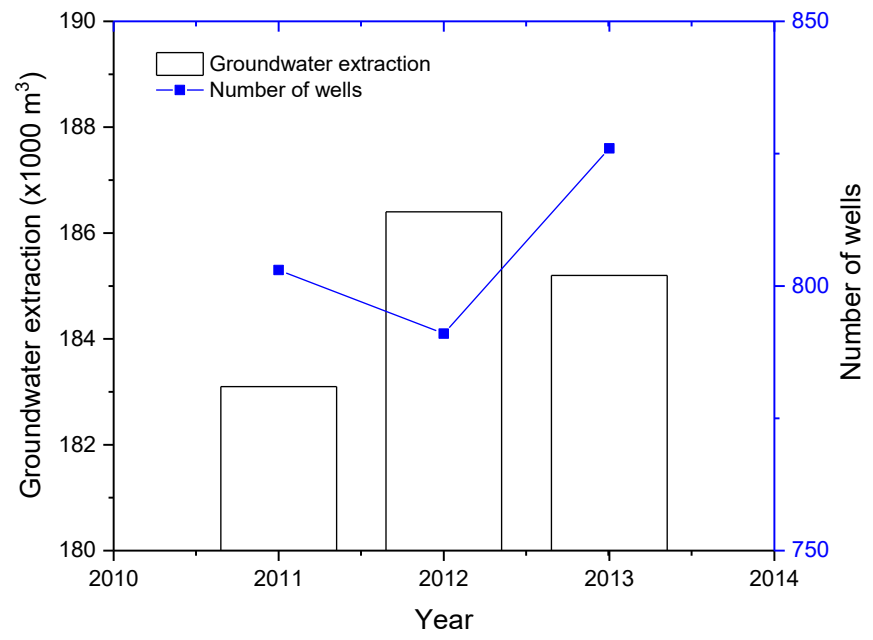

Fig. 6. Groundwater extraction and number of the wells in Denpasar from 2011-2013 [12].

The number of wells and the groundwater extraction data can be estimated from the Denpasar Public Works' Report (PU). Figure 6 shows the volume of groundwater extractions and the number of wells in Denpasar for three years (2011, 2012, and 2013) [12]. The number of wells decreased in 2012. However, the volume of groundwater 
extraction increased. In contrast to the year 2012, the number of wells increased in 2013, but the amount of groundwater extraction decreased. There is no correlation between the number of wells and the amount of groundwater extraction. Data gathered over a longer period are needed in order to obtain a better temporal perspective of the groundwater extractions. However, the required data are not available at the present time. Further investigation is needed to reveal the mechanism of the subsidence. Other factors, such as changes in land use and land cover (LULC), will also need to be known. There are rapid changes occurring in the use of land in Denpasar, for example, from paddy fields to built-up residential areas [13], which may cause land subsidence due to loading on the ground. In turn, the withdrawal of groundwater by people living in these new residential areas will also trigger land subsidence.

\section{Conclusion}

This study has shown the main advantages of the SBAS DInSAR method. It can monitor the ground subsidence over an extensive area without the need for any sensor installation on the ground. The screening to find the displacement over a large area can be conducted efficiently by using SBAS DInSAR prior to carrying out a detailed investigation. By applying the SBAS DInSAR method using 118 Sentinel-1A/B SAR data images from October 2014 - June 2019, the presence of "silent subsidence" (the present subsidence that nobody notices) was detected in Denpasar Selatan, Denpasar Barat, and Kuta districts. Large subsidence ( $-150 \mathrm{~mm}$ to $-200 \mathrm{~mm}$ ) was found to have occurred over areas of $3.21 \mathrm{ha}$ and $89.82 \mathrm{ha}$, and moderate subsidence $(-100 \mathrm{~mm}$ to $-150 \mathrm{~mm})$ was found to have occurred in another areas. From the subsidence transition at the points of interest (POI), the subsidence seems to increase linearly. More attention to the area is recommended. Further investigation is required, such as installing accurate measurement devices (i.e., GPS sensors) in areas with larger subsidence. This action will also be effective for confirming the accuracy of the SBAS DInSAR results. This method has been successful in revealing the presence of unnoticed subsidence, but its mechanism remains unclear due to a lack of data, such as data on the locations of the wells, including groundwater extraction data and a detailed geological map. Other factors, such as changes in land use and land cover (LULC), need to be considered. More detailed investigations of the subsidence in Denpasar and the surrounding area will be the subject of future work.

This research was supported by JSPS KAKENHI (Grant-in-Aid for Scientific Research, Japan Society for the Promotion of Science) Grant Number 16H03153. All the Sentinel-1A/B SAR data used in this research were kindly provided by the European Space Agency (ESA) and downloadable from the Alaska Satellite Facility (ASF). The ALOS Global Digital Elevation Model (AW30DEM) data were provided by the Japan Aerospace Exploration Agency (JAXA). The administration boundaries data were provided by Open Street Map (OSM). Many thanks are extended to these institutions. Thank also for collaboration research between Yamaguchi University, Japan and Udayana University, Indonesia. They also extend their thanks to Ms. H Griswold for proofreading this paper.

\section{References}

1. N. Shimizu, S. Nakashima, T. Masunari, Rock Mechanic Rock Engineering 47, 313328 (2014)

2. P. Berardino, G. Fornaro, R. Lanari, E. Sansosti, IEEE Transaction Geoscience Remote Sensing 40, 2375-2383 (2002)

3. P. E. Yastika, N. Shimizu, H. Z. Abidin, Advance Space Research 63, 1719-1736 (2019) 
4. BPS, Bali Province in Figures (BPS-Statistic of Bali Province, 2016)

5. M. M. Purbo-Hadiwidjojo, H. Samodra, T. C. Amin, Geological Map of the Bali Sheet, (Bali 1707 \& 1807, (1:250000)) (1998)

6. A. Ferretti, A. Monti-Guarnieri, C. Prati, F. Rocca, InSAR Principles: Guidlines for SAR Interferometry Processing and Interpretation (ESA Publications, 2007)

7. A. Ferretti, C. Prati, F. Rocca, IEEE Transaction Geoscience Remote Sensing 39, 8-20 (2001)

8. R. M. Goldstein, C. L. Werner, Geophysics Research Letter 25, 4035-4038 (1998)

9. M. Costantini, IEEE Transaction Geoscience Remote Sensing 36, 813- 821 (1998)

10. L. Ge, A. H. M. Ng, X. Li, Remote Sensing Environment 154, 46-60 (2014)

11. H. Z. Abidin, H. Andreas, R. Djaja, D. Daramawan, M. Gamal, GPS Solution 12, 23 32 (2008)

12. PU Denpasar, Laporan akhir tahun 2014 Kajian teknis pengelolaan air tana Kota Denpasar (government report, 2014) in Bahasa

13. N. Supardan, W. Ambarwulan, M. Panularsih, In:FIG Working Week-2017 (2017) 